\title{
IS MEASURING INTRAOCULAR PRESSURE NECESSARY ON THE FIRST POST-OPERATIVE DAY FOLLOWING UNCOMPLICATED CATARACT SURGERY?
}

\author{
N. H. V. CHONG, R. K. AGGARWAL, P. SHAH and P. I. MURRAY \\ Birmingham
}

\begin{abstract}
SUMMARY
A prospective study was undertaken to assess whether the level of intraocular pressure (IOP) on the first day after cataract surgery could be estimated by clinical examination only, thereby removing the need for applanation tonometry. A total of $\mathbf{7 0}$ patients underwent uncomplicated extracapsular cataract extraction and intraocular lens implantation. The following day a Consultant, Registrar and Senior House Officer were asked to identify those patients with significantly raised IOP $(>27 \mathrm{mmHg})$ using slit lamp examination only. A fourth examiner, masked to the assessments of the three observers, measured the IOP using the Goldmann applanation tonometer. Pressures of $>27 \mathbf{~ m m H g}$ by Goldmann tonometry were found in $\mathbf{1 0}$ patients $(14 \%)$ of which $8(80 \%)$ were missed by all three ophthalmologists. Formal measurement of IOP appears a necessary part of the post-operative assessment after uncomplicated cataract surgery.
\end{abstract}

An intraocular pressure (IOP) rise within 24 hours of extracapsular cataract extraction and intraocular lens implantation $^{1-7}$ is well documented, particularly after the use of sodium hyaluronate. ${ }^{7}$ In some cases, medical therapy is required to reduce the risk of ocular complications such as anterior ischaemic optic neuropathy ${ }^{8}$ and central retinal vein occlusion. ${ }^{9}$ IOP measurement is routinely performed on the first post-operative day yet there are theoretical risks in doing so during this early period, namely corneal abrasion and cross-infection.

High IOP in the early post-operative period following cataract surgery may be associated with several clinical signs that can be assessed by slit lamp examination, such as corneal epithelial oedema, corneal striae, excessive anterior chamber activity and the presence of in situ sodium hyaluronate.

A prospective study was undertaken to see whether it is necessary to measure IOP on the first post-operative day following uncomplicated cataract surgery.

Correspondence to: $\mathrm{Mr}$ P. I. Murray, Academic Unit of Ophthalmology, Birmingham and Midland Eye Hospital. Church Street, Birmingham B3 2NS, UK

\section{PATIENTS AND METHODS}

Over a 10-week period, consecutive patients admitted for cataract surgery under one Consultant at the Birmingham and Midland Eye Hospital were included in the study. Patients with previous ocular surgery or glaucoma were excluded. A total of 70 patients (42 females and 28 males with a mean age of 72 years) underwent uncomplicated extracapsular cataract extraction with posterior chamber intraocular lens implantation. Sodium hyaluronate was used on each patient and every effort was made to remove it completely at the end of surgery.

On the first post-operative day, a Consultant, Registrar and Senior House Officer (SHO) independently attempted to estimate the IOP by slit lamp examination only. Patients were subdivided into three groups: group 1, normal IOP $(<22 \mathrm{mmHg})$; group 2, moderately raised IOP (22$27 \mathrm{mmHg})$; group 3, significantly raised IOP $(>27 \mathrm{mmHg})$. The IOP was then measured using the Goldmann applanation tonometer by a fourth examiner unaware of the findings of the other three examiners. The assessed IOP grouping of the three observers was compared with the true IOP grouping based on the Goldmann applanation tonometer measurements.

\section{RESULTS}

From the Goldmann applanation tonometer measurements, there were 54 patients with normal IOP $(<22 \mathrm{mmHg}), 6$ patients with moderately raised IOP (22$27 \mathrm{mmHg}$ ) and 10 patients with significantly raised IOP ( $>27 \mathrm{mmHg}$ ).

In the assessed grouping, the Consultant put 57 patients into group 1, 9 into group 2 and 4 into group 3. Although both the Registrar and the SHO put 57 patients into group 1,8 into group 2 and 5 into group 3, they did not put the same patients in each group. The breakdown of the results by the three observers is shown in Table I.

By comparing the patients with IOP $>27 \mathrm{mmHg}$ by applanation tonometry with those thought to be in group 3 by the observers, 8 patients $(80 \%)$ were missed by all three 
Table I. Comparison of the true and assessed IOP grouping of the three observers

\begin{tabular}{|c|c|c|c|}
\hline \multirow{2}{*}{$\begin{array}{l}\text { Assessed } \\
\text { groups }\end{array}$} & \multicolumn{3}{|c|}{ True groups } \\
\hline & Group 1 & Group 2 & Group 3 \\
\hline \multicolumn{4}{|l|}{ Consultant } \\
\hline Group 1 & 48 & 2 & 7 \\
\hline Group 2 & 5 & 3 & 1 \\
\hline Group 3 & 1 & 1 & 2 \\
\hline \multicolumn{4}{|l|}{ Registrar } \\
\hline Group 1 & 48 & 2 & 7 \\
\hline Group 2 & 3 & 4 & 1 \\
\hline Group 3 & 3 & 0 & 2 \\
\hline \multicolumn{4}{|c|}{ Senior House Officer } \\
\hline Group 1 & 48 & 3 & 6 \\
\hline Group 2 & 4 & 2 & 2 \\
\hline Group 3 & 2 & 1 & 2 \\
\hline
\end{tabular}

Group 1, normal IOP $(<22 \mathrm{mmHg})$; group 2. moderately raised IOP (22-27 $\mathrm{mmHg})$; group 3 , significantly raised IOP (>27 mmHg).

ophthalmologists. Conversely, of those patients thought to have IOP $>27 \mathrm{mmHg}$ by slip lamp examination only, the Consultant, Registrar and SHO were correct in only $50 \%$, $40 \%$ and $40 \%$ of patients respectively.

\section{DISCUSSION}

Transient rise in IOP after cataract surgery is well recognised $^{1-7}$ and was initially described by Gormaz ${ }^{1(1)}$ as early as 1962. Certain factors that may influence IOP elevation are watertight wound closure, ${ }^{11}$ damage to the trabecular meshwork, ${ }^{12,13}$ prostaglandin production. ${ }^{1+}$ inflammatory debris, peripheral anterior synechiae, hyphaema' and the use of viscoelastic material such as sodium hyaluronate.

The differences between the assessments of the three observers were small, with the overall percentage agreement between the Consultant, Registrar and SHO being $75.7 \%, 77.1 \%$ and $74.3 \%$ respectively. Furthermore, the ability of the observers to identify the patients without significantly raised IOP (specificity) was also high at $96.7 \%$. $95.0 \%$ and $95.0 \%$ respectively. Nevertheless, $80 \%$ of patients with IOP $>27 \mathrm{mmHg}$ were missed.

During the study it was noted that some patients with significantly raised IOP had no abnormal signs on slit lamp examination, which made their identification difficult. Also, some patients with normal pressure had corneal oedema which might have been related to surgical trauma. This may explain the high percentage of 'false positive' group 3 patients found by each observer.

With the current trend towards day case surgery, it may not be long before large numbers of cataract extraction will be carried out as day cases. Thomas et al. ${ }^{15}$ suggested at least $20 \%$ of cataract operations should be day cases and this figure is probably an underestimate. Whilst most units would ask patients to return to hospital for post-operative assessment, some units have found that this can be performed by trained nurses. ${ }^{16,17}$

This study illustrates the difficulty in assessing IOP using slit lamp examination only, even by experienced ophthalmologists. Nevertheless, it is important to identify and treat these patients in order to prevent ocular mor- bidity. Post-operative assessment should, therefore, include an accurate IOP measurement. If nursing staff are involved in post-operative assessment, they should be trained to perform this task.

We are grateful to Helen S. Jones for statistical advice.

Key words: Cataract surgery, Intraocular pressure, Measurement.

\section{REFERENCES}

1. Kooner KS, Dulaney DD, Zimmerman TJ. Intraocular pressure following extracapsular cataract extraction and posterior chamber intraocular lens implantation. Ophthalmic Surg 1988; 19:471-4.

2. Gupta A. Bansal RK, Grewal SPS. Natural course of intraocular pressure after cataract extraction and the effect of intracameral carbachol. J Cataract Refract Surg 1992;18: $166-9$.

3. Gross JG, Meyer DR, Robin AL, et al. Increased intraocular pressure in immediate postoperative period after extracapsular cataract extraction. Am J Ophthalmol 1988;105: 466-9.

4. Heslin KB, Guerriero PN. Extracapsular cataract extraction and primary posterior chamber lens implantation. J Cataract Refract Surg 1986;12:44-6.

5. Alpar JJ. Glaucoma after intraocular lens implantation: survey and recommendations. Glaucoma 1986;7:241-5.

6. Hollands RH, Drance SM, Schulzer M. The effect of acetylcholine on early postoperative intraocular pressure. Am J Ophthalmol 1987;103:749-53.

7. Naeser K, Thim K. Hansen TE, et al. Intraocular pressure in the first day after implantation of posterior chamber lenses with the use of sodium hyaluronate (Healon). Acta Ophthalmol 1986:64:330-7.

8. Hayreh SS. Anterior ischaemic optic neuropathy. IV. Occurrence after cataract surgery. Arch Ophthalmol 1980:98: $1410-6$.

9. Vannes S, Tarkkanen A. Retinal vein occlusion and glaucoma: tonographic study of the incidence of glaucoma and its prognostic significance. Br J Ophthalmol 1960;44: 583-9.

10. Gormaz A. Ocular tension after cataract surgery: with special reference to the phenomenon of late hypotony. Am J Ophthalmol 1962:53:832-41.

11. Jaffe NS. Glaucoma in aphakia. In: Cataract surgery and its complications. St Louis: CV Mosby, 1981:317-9.

12. Campbell DG. Grant WM. Trabecular deformation and reduction of outflow facility due to cataract and penetrating keratoplasty sutures. Invest Ophthalmol Vis Sci 1977:16 (Suppl): 126 .

13. Kirsch RE, Levine O. Singer JA. The ridge at the internal edge of the cataract incision. Trans Am Acad Ophthalmol Otolaryngol 1977:83:224-7.

14. Rich WJ. Prevention of postoperative ocular hypertension by prostaglandin inhibitors. Trans Ophthalmol Soc UK 1977:97:268-72.

15. Thomas HF, Humphry R. Day surgery for cataracts. BMJ 1992;305:536-7.

16. Ingram RM, Banerjee D, Traynar MJ, Thompson RK. Daycase cataract surgery. Br J Ophthalmol 1983;67:278-81.

17. Lowe KJ, Gregory PA. Jeffrey RI. Easty DL. Patient perceptions and social impact: preliminary results of the Bristol MRC survey. Eye 1991;5:373-8. 